\title{
Future Reference in Hungarian
}

\author{
Nicole Palffy-Muhoray \\ Yale University
}

\section{Introduction}

This paper provides a semantic analysis of future-referring expressions in Hungarian in which the available interpretations of such expressions follow from the interaction of their temporal properties with the aspectual properties of Hungarian predicates.

\subsection{Future-referring expressions in Hungarian}

In Hungarian there are three types of expressions that can give rise to future reference. These are the future copula, the auxiliary fog, and the non-past construction. The future copula, shown in (1), is a future form of the copula van, which has distinct past, present, and future forms, and inflects for person and number. It also has an imperative form, and can inflect for mood. The future form occurs only with adjectival predicates and locates states in the future of the speech time. The copula is the only verb in the language that has an inflected future form.

(1) a. János magas lesz

john tall be.FUT.3SG

'John will be tall'

Future copula

This paper deals mainly with the remaining two expressions that give rise to future reference. These are the fog and the non-past construction. The fog construction involves a future marker fog and gives rise to future reference obligatorily 


\section{Nicole Palffy-Muhoray}

in all contexts. Fog is an auxiliary verb which conjugates for person and number and is followed by the infinitival form of a main verb, as in (2).
(2) A buli-ba fog-unk
menni (ma este)
the party-ILL fog-NPST.1 PL.INDEF go.INF (today evening)
'We will go to the party (this evening)' 1
fog construction

The non-past construction can give rise to future reference without overt future marking, as shown in (3a). Non-past sentences involve a finite verb conjugated for subject person and number, and object definiteness. §2 shows that whether or not future-oriented readings are available is dependent on the aspectual properties of the predicate. When future-oriented readings are unavailable, the non-past gives rise to ongoing readings, as in (3b).
a. János meg-föz-i
a csirkét ma este
john PART-cook-NPST.3SG DEF chicken.ACC today evening
'John will cook the chicken this evening'
b. János meg-föz-i a csirkét
john PART-cook-NPST.3SG DEF chicken.ACC
'John is cooking the chicken'

\subsection{Future reference}

There has been a long-standing tradition of viewing expressions which can receive future-oriented interpretations as involving future tense. At its most basic, a tense is a grammatical marker which locates eventualities in time. The following are properties commonly attributed to the tenses on a generous view of what can be considered a tense.

(4) A tense is:

a. A systematically used grammatical marker, often involving verbal inflectional morphology, a particle, or auxiliary.

b. Obligatory in clauses that convey temporal information, at least in unmarked contexts.

c. Usually unable to co-occur with other tenses. (Smith (2008), Hayashi (2011))

The perspective that tense is generally responsible for the contribution of temporal reference and temporal location of events faces a serious empirical problem,

\footnotetext{
${ }^{1}$ I use the following notations for glosses in addition to standard person and number abbreviations: NPST $=$ non-past construction, DEF $=$ definite object marker, INDEF $=$ indefinite object marker, INF $=$ infinitive marker, PART $=$ particle, ILL $=$ illative case marker, TEM $=$ temporal case, INE $=$ inessive case marker, $\mathrm{ACC}=$ accusative case marker, $\mathrm{DAT}=$ dative marker, $\mathrm{ADE}=$ adessive case marker, ALL $=$ allative case marker.
} 


\section{Future Reference in Hungarian}

however. Cross-linguistically, future reference is commonly achieved through the use of expressions with no overt future marking. The Hungarian n non-past is just one such example(Lotz (1962), Papp (1989), Dahl (2000), Abondolo (1998)). In fact, it is possible that true future tense is cross-linguistically rare ..

Future reference without future marking has been a topic of growing interest in recent years, and increasing consideration has been given to the following frequently encountered forward-shifting mechanisms in languages where future reference occurs without grammaticalized future markers (Dahl (2000), Bittner (2005), Tonhauser (2009)).

(5) a. Forward-shifting grammatical and lexical aspect (especially prospective aspect)

b. Future-referring temporal adverbs

c. Future time contexts

As a result of the new perspectives offered by these works on the semantics of future reference, any analysis of future reference in any language should minimally grapple with the following three questions.

(6) a. How is future reference accomplished without future marking?

b. How do aspectual properties of the predicate and aspectual markers impact future reference?

c. How do other features of the language that impact future reference (such as context, temporal adverbs, and modals) work, and what effects do they have on the forward-shifting of events?

This paper focuses predominantly on the first two questions, providing an illustration of the main future-referring expressions in Hungarian and proposing a semantics for the elements involved, as well as for non-past and fog sentences with temporal adverbs.

\subsection{Roadmap \& Claims}

$\S 2$ of this paper presents the Hungarian non-past and fog constructions in more detail and discusses the distributional patterns of future-oriented interpretations which proves relevant for this analysis. Specifically, I argue that aspectual properties of predicates interact with the meaning of the non-past construction to give rise to ongoing reading and future readings, and it is this interaction which is responsible for the distributional contrasts between the interpretations of the non-past and fog constructions. The forward-shifting of the event time in the fog construction, on the other hand, is part of the meaning of the morpheme fog. In $\$ 3$ I present a semantics for fog and the non-past which gives rise to the expected restrictions on intepretations when it interacts with telic predicates and temporal adverbs. 


\section{Nicole Palffy-Muhoray}

\section{The Hungarian facts}

\subsection{The fog construction}

The fog construction, shown in (7) with a range of predicate types, obligatorily gives rise to future reference in all contexts.

a. János lak-ni fog NY-ban

john live-INF fog.NPST.3SG.INDEF NY-INE

'John will live in NY'

State

b. János $t v$ - $t$ néz-ni fog

john tv-ACC watch-INF fog.NPST.3SG.INDEF

'John will watch tv'

Durative, Atelic (Activity)

c. A buli-ba fog-unk menni

the party-ILL fog-2PL.INDEF go.INF

'We will go to the party'

Durative, Telic (Accomplishment)

d. Miklos el-felejteni fogja a leckét

michael PART-forget.INF fog.NPST.3SG.INDEF DEF lesson.ACC

'Michael will forget the lesson' Non-durative, Telic (Achievement)

The fact that fog always gives rise to future reference means that sentences like that in (8) are unacceptable.

\section{(8)}

\#Tegnap amikor haza-jöttem, Attila mond-ta

yesterday when PART-come.PST.1SG.INDEF, attila this.ACC

hogy valamítfog énekel-ni

say-PST.3SG.DEF that something.ACC fog.NPST.3SG.INDEF sing-INF

\#'Yesterday when I got home, Attila said that he will sing something'

If $f \circ g$ were a prospective aspect marker, locating the reference time in the future of the event time, we would expect such sentences to be possible. The fact that they are not rules out the possibility that fog is a prospective aspect marker.

There is no evidence of restrictions on the flavor of futurity with which fog can be used. (9a) shows fog with a scheduled future. (9b) shows an unscheduled prediction future. (9c) shows an intention future where the speaker is the agent of the action, and (9d) shows an intention future where the speaker is not the agent.

a. 3-kor indul-ni fog a vonat

3-at set.out-INF fog.NPST.3SG.INDEF DEF train

'The train will leave at 3'

Scheduled future

b. Es-ni fog az esó

fall-INF fog.NPST.3SG.INDEF DEF rain

'It will rain'

Non-scheduled prediction future 


\section{Future Reference in Hungarian}

c. Fog-ok haza-menni a buli után

fog-NPST.1SG.INDEF PART-go.INF DEF party after

'I will go home after the party'

Speaker intention

d. Rékafog haza-menni a buli után

réka fog-NPST.3SG.INDEF PART-go.INF DEF party after

'Réka will go home after the party' Non-speaker agent intention

\subsection{The Non-past construction}

Hungarian shows a prominent past/non-past tense distinction, which is obligatorily marked in finite clauses. The Hungarian past tense is marked with a suffix on the verb, the form of which varies considerably depending on the final sounds of the verb involved, the person and number of the subject, the definiteness of the object, and vowel harmony, as in (10).
a. Péter vett
a könv-et
peter buy.PST.3SG.INDEF DEF book-ACC
'Peter bought the book'
3 sg subject, definite object
b. Vesztunk egy új kocsít
buy.PST.1PL.INDEF INDEF new car.ACC
'We bought a new car'
Ipl subject, indefinite object
$\begin{array}{ll}\text { c. Zoltán fel-hívta } & a \text { Péter-t } \\ \text { zoltan PART-call..PST.3SG.DEF DEF peter-ACC }\end{array}$
'Zoltán called up Peter'
3sg subject, definite object

Morphologically, the non-past has no overt tense marking. Person and number of subject and definiteness of object are marked on the verb, as with the past tense. Non-past future-referring sentences often contain temporal frame adverbs, as in (11).
a. Péter alszik
ma este
peter sleep.NPST.3SG.INDEF today evening
'Peter will sleep this evening'
b. Jövö év-ben János lak-ik NY-ban
next year-INE John live-NPST.3SG.INDEF NY-INE

'Next year John will live in NY'

The temporal frame adverbial majd is very often used with non-past futurereferring sentences when the exact temporal location of the event is unknown or irrelevant. Majd has a variety of meanings, all of which are constrained to the future, some of which are similar to: 'soon' (as in (12)), 'then', 'presently', 'in time', and just simply 'in the future'. 


\section{Nicole Palffy-Muhoray}

(12) Majd veszek neked egybiciklít

In.the.future buy.NPST.1SG DAT.2SG a bicycle.ACC

'I will buy you a bicycle.'

\subsection{Aspect and the non-past}

As we have seen, the non-past construction is compatible with both a future and an event-in-progress reading. Note that in (13b), a future-oriented context would allow the sentence to give rise to a future reading. Without such a context, future-oriented readings are unavailable.

a. János zongorázik holnap délután

john play.piano-NPST.3SG.INDEF tomorrow afternoon

'John will play the piano tomorrow afternoon'

Future

b. János zongorázik

john play.piano-NPST.3SG.INDEF

'John is playing the piano'

Event-in-progress

A closer look at the distribution of future-referring and event-in-progress readings of non-past sentences reveals that the availability of future referring interpretations with non-past sentences is crucially tied to the aspectual properties of the predicate.

Atelic non-past sentences (both stative and eventive) and non-durative non-past sentences produce event-in-progress readings, as in (14a), (14b), and (14c). In the presence of adverbs ${ }^{2}$, these sentences obligatorily give rise to future reference, as seen above in (13a). Durative telic (accomplishment) non-past sentences, on the other hand, give rise to future readings even without temporal adverbs, as in (14d).

a. Magda szeret- $i \quad$ a Zolít

magda love-NPST.3SG.DEF DEF zoli.ACC

'Magda loves Zoli'

Atelic (Stative)

b. Tanul-unk study-NPST.1PL.INDEF

'We are studying'

Atelic (Eventive)

c. János kap-ja az ajándék-ot

john receive-3SG.NPST.DEF the present-ACC

'John is getting a present (currently)'

Non-durative Telic

d. Lilla el-olvas-ja a könyv-et

Lilla PV-read-3SG.NPST.DEF the book-ACC

'Lilla will read the book'

Durative Telic

${ }^{2}$ Future contexts have the same effect of eliminating the ongoing interpretation as temporal adverbs do. 


\section{Future Reference in Hungarian}

Telicity is defined formally as in (15), following Krifka (1998).

$$
\operatorname{TELIC}(\mathrm{X}) \longleftrightarrow \forall e, e^{\prime}\left[X(e) \wedge X\left(e^{\prime}\right) \rightarrow \neg e^{\prime}<e\right]
$$

For any 2 events, if they are in the predicate $X$, one cannot be a proper subevent of the other.

The pattern described above can be seen not only through speaker judgements, but also through the distribution of telic and atelic predicates with non-past and fog sentences in Hungarian texts. The table in (16) shows the percentages of telic and atelic sentences from a number of future-referring sentences gathered by hand from a variety of texts ${ }^{3}$. (16) shows that $84 \%$ of future-referring non-past sentences are telic, while only $16 \%$ of future-referring non-past sentences are telic. This is a significant numerical asymmetry, and warrants an explanation. I include the fog sentences to reflect that the asymmetry in the number of telic and atelic non-past sentences is not likely to be a fact about the language in general. With fog sentences, atelic predicates are significantly more common than telic predicates, providing further incentive to provide an explanation of future reference that explains the asymmetry between future-referring non-past sentences.

\begin{tabular}{|l|c|c|}
\hline & Telic & Atelic \\
\hline \hline non-past $(\mathrm{n}=51)$ & $\mathbf{8 4 \%}$ & $\mathbf{1 6 \%}$ \\
\hline fog $^{4}(\mathrm{n}=101)$ & $\mathbf{3 7 \%}$ & $\mathbf{6 3 \%}$ \\
\hline
\end{tabular}

In short, the empirical claim of this section is that atelic and non-durative predicates give rise to event-in-progress readings with the non-past construction, while durative telic predicates give rise to future interpretations with the non-past. $\$ 3$ provides a semantics which accounts for this distribution.

\section{Analysis of the temporal components of the non-past (and fog)}

In this section I propose a formal analysis of the temporal components of the fog and non-past construction. The distributional differences in future-referring interpretations between telic and atelic predicates with these constructions falls out from the interaction of telicity with the meaning of fog and the non-past.

\subsection{The semantics of the fog construction}

Instantiation of predicates with respect to a world and time is defined here in terms of the AT relation, adapted from Condoravdi 2002. This definition reflects that

\footnotetext{
3 The tables are based on 152 future-referring non-past and fog sentences that were systematically gathered from from fables (Minden napra egy mese by T. Aszódi Éva), a novel (Édes Anna by Kosztolányi Dezső ), blogs, web-based news sources, and biblical texts (http://spiritlessons.com/Documents/Bible/Hungarian_HTML_Bible/index.htm with English translations from the correlated online American Standard bible at http://www.htmlbible.com/asv/index.htm.
} 


\section{Nicole Palffy-Muhoray}

fog and the non-past can take either eventive predicates or temporal predicates, as shown in (17).

$$
\operatorname{AT}(P, i)=\left\{\begin{array}{lr}
\exists e[P(e) \wedge \tau(e) \subseteq i] & \text { Eventive } \\
P(i) & \text { Temporal }
\end{array}\right.
$$

As we have seen, the fog construction always gives rise to future reference. I take $f o g$ to be a simple existential quantifier over future intervals, as in (18).

$$
\llbracket \mathrm{FOG} \rrbracket: \lambda P \lambda w . \forall w^{\prime}\left[w^{\prime} \in \mathrm{MB}(w, n o w) \longrightarrow w^{\prime} \in \exists i[i>\text { now } \wedge A T(P, i)]\right]
$$

Fog takes eventive or temporal predicates and returns a set of propositions such that for every world in the modal base (MB) with respect to the evaluation world at the now of speech time, those worlds are also worlds in which the proposition holds at some interval after now.

A sample derivation of a fog sentence is given in (19). (19a) shows the Hungarian sentence and its English translation. In (19b) contains the eventuality description. (19c) shows FOG applied to the eventuality description and the steps and result of the application.

\section{a. János fut-ni fog}

john run-INF FOG.NPST.3SG.INDEF

'John will run'

b. $\llbracket$ john run $\rrbracket=\lambda e$.john-run $(e)$

c. $\llbracket \mathrm{FOG}($ john run $) \rrbracket=\lambda P \lambda w . \forall w^{\prime}\left[w^{\prime} \in \mathrm{MB}(w\right.$, now $) \longrightarrow w^{\prime} \in \exists i[i>$ now $\wedge$ $A T(P, i)]](\lambda e . j o h n \operatorname{run}(e))$

$$
\begin{aligned}
& =\lambda w \cdot \forall w^{\prime}\left[w^{\prime} \in \operatorname{MB}(w, \text { now }) \longrightarrow w^{\prime} \in \exists i[i>\text { now } \wedge A T(\lambda e \text {.john } \operatorname{run}(e), i)]\right] \\
& =\lambda w . \forall w^{\prime}\left[w^{\prime} \in \operatorname{MB}(w, \text { now }) \longrightarrow w^{\prime} \in \exists i[i>\text { now } \wedge \exists e . j \operatorname{john} \operatorname{run}(e) \wedge \tau(e) \subseteq\right. \\
& i]]
\end{aligned}
$$

In (19), the predicate holds of some interval $i$ that is after now. In other words, 'john run' is true of some period of time that occurs after the time of speech.

Note that the telicity or atelicity of a predicate has no effect on the forwardshifting properties of fog. This is ideal. Though there was a distributional asymmetry between telic and atelic fog sentences (seen in (16) in §3), this is not a problem. Rather, the asymmetry is an epiphenomenon resulting from the interaction of the non-past with atelic predicates. Atelic predicates with the non-past give rise to an event-in-progress reading, meaning that in order to get a future reading with atelic predicates, either temporal adverbs or the fog construction is needed. This is not so with telic predicates, which give rise to future reference with the non-past. As a result, it is no surprise that the fog construction would be used more often with atelic predicates than with telic predicates. 


\section{Future Reference in Hungarian}

\subsection{The non-past with atelic predicates}

I propose the following meaning for the non-past construction in Hungarian, which is compatible with both future and event-in-progress readings.

$$
\llbracket \mathrm{NPAST} \rrbracket=\lambda P \lambda w . \forall w^{\prime}\left[w^{\prime} \in \operatorname{MB}(w, n o w) \longrightarrow w^{\prime} \in \operatorname{AT}(P,[n o w, \infty))\right]
$$

NPAST denotes a function from eventive or temporal predicates to a set of worlds in the modal base such that these worlds are all worlds where $P$ holds in the interval extending from the now of speech time to infinitely in the future. A derivation of the atelic predicate 'john-run' is given in (21).

a. János fut

john run.NPST.3SG.INDEF

'John runs'

b. $\quad$ john-run $\rrbracket=\lambda e . j o h n-\operatorname{run}(e)$

c. $\llbracket \operatorname{NPAST}($ john-run $) \rrbracket=\lambda P \lambda w . \forall w^{\prime}\left[w^{\prime} \in \operatorname{MB}(w\right.$, now $) \longrightarrow w^{\prime} \in \operatorname{AT}(P,[$ now,$\left.\infty))\right](\lambda e . j o h n-$ $\operatorname{run}(e))$

$$
\begin{aligned}
& =\lambda w \cdot \forall w^{\prime}\left[w^{\prime} \in \operatorname{MB}(w, \text { now }) \longrightarrow w^{\prime} \in \operatorname{AT}(\lambda e[\operatorname{john}-\operatorname{run}(e),[\text { now }, \infty)])\right] \\
& =\lambda w \cdot \forall w^{\prime}\left[w^{\prime} \in \operatorname{MB}(w, \text { now }) \longrightarrow w^{\prime} \in \exists e[\operatorname{john}-\operatorname{run}(e) \wedge \tau(e) \subseteq[\text { now, } \infty)]\right]
\end{aligned}
$$

In the denotation of NPAST given in (20), the AT relation holds between $P$ and the interval $[$ now,$\infty)$. This has the effect of restricting the time interval over which the predicate can hold to the interval starting from the speech time and extending infinitely into the future. Because the AT relation requires that the temporal trace of the $P$ event must be a subpart of this larger interval, the temporal trace could have one of the following three relationships to now:

1. $\tau(e) \subseteq$ now

2. $\tau(e)>$ now

3. $\tau(e) \subseteq i \wedge$ now $\subseteq$ ini $i$

Atelic predicates can hold in the interval $[$ now, $\infty)$ in any of the three ways given in (22). Telic predicates, on the other hand, are restricted in how they can hold in $[$ now,$\infty)$.

\subsection{The non-past with durative telic predicates}

(23) shows the derivation of a durative telic sentence with the non-past. (23a) shows the Hungarian sentence and English translation. (23b) gives the eventuality description, and (23c) shows the non-past applied to the eventuality description. 


\section{Nicole Palffy-Muhoray}
a. Lászlófel-mossa
a padlót

laszlo PV-wash.NPST.3SG.DEF the floor.ACC

'Laszlo washes up the floor'

b. $\llbracket$ laszlo-washes-up-the-floor $\rrbracket=\lambda e$.laszlo-washes-up-the-floor $(e)$

c. $\llbracket$ NPAST (laszlo-washes-up-the-floor) $\rrbracket=\lambda w \cdot \forall w^{\prime}\left[w^{\prime} \in \operatorname{MB}(w, n o w) \longrightarrow w^{\prime} \in\right.$ $\operatorname{AT}(\lambda e[$ laszlo-washes-up-the-floor $(e),[$ now,$\infty))]]$

$$
\begin{aligned}
& =\lambda w . \forall w^{\prime}\left[w^{\prime} \in \operatorname{MB}(w, \text { now }) \longrightarrow w^{\prime} \in \exists e[\text { laszlo-washes-up-the-floor }(e) \wedge\right. \\
& \tau(e) \subseteq[\text { now }, \infty)]]
\end{aligned}
$$

We still need to derive the fact that durative telic non-past sentences give rise to future interpretations, not ongoing interpretations. In $\$ 2$, the definition of telicity was provided, and is repeated here in (24).

$$
\operatorname{TELIC}(\mathrm{X}) \longleftrightarrow \forall e, e^{\prime}\left[X(e) \wedge X\left(e^{\prime}\right) \rightarrow \neg e^{\prime}<e\right]
$$

For any 2 events, if they are in the predicate $X$, one cannot be a proper subevent of the other.

As shown in $\S 2$, telic predicates give rise to future interpretations with the nonpast, and I argue that it is the interaction of telicity with the meaning of the non-past which produces this distribution. However, the definition of telicity in (24) is one which quantifies over events. This is incompatible with the AT relation, which deals with intervals. As a result, I introduce a version of (24) for intervals, called the Anti-subinterval Property. This is given in (25).

Anti-subinterval Property: $\left.\forall i, i^{\prime} \exists e\left[\operatorname{AT}(P, i) \wedge \operatorname{AT}\left(P, i^{\prime}\right)\right) \rightarrow \neg\left(i^{\prime} \subset i\right)\right]$

The Anti-subinterval property is useful in understanding why durative telic predicates can't give rise future interpretations. I will show that durative telic predicates cannot hold over $[$ now, $\infty)$ as in possibility 1 in (22). The result is that they cannot give rise to event-in-progress readings with the non-past, which accords with the data. The reasoning is as follows:

- Durativity of a predicate means that for some interval and some $P$ event, the temporal trace of that event is equal to the interval. Formally, $\exists i \exists e[P(e) \wedge$ $\tau(e)=i]$

- If the $i$ in question (the $i$ over which $P$ is true) is ongoing at speech time, the moment of speech time is a subinterval of the interval over which $P$ holds.

- Accomplishments (durative telic predicates), as in (23), have the Anti-subinterval Property. 


\section{Future Reference in Hungarian}

- If $P$ has the Anti-subinterval Property, then $P$ holds of no proper subinterval of $i$, in particular, not now.

- Therefore, possibility 1 in (22) is not available for accomplishments.

Note that non-durative telic predicates can hold of the speech time as in (22a). Because of their punctuality, they can hold of now of any subsequent interval.

\subsection{The non-past with temporal predicates}

All predicates receive a future interpretation when they occur with temporal adverbs and the non-past. Temporal adverbs take eventive predicates and return temporal predicates ( Abusch (1998), Condoravdi (2002), Deo (2009)). The meaning of 'tomorrow' is given in $(27 \mathrm{~d})$ :

$$
\llbracket \text { TOMORROW } \rrbracket=\lambda P \lambda i . \mathrm{AT}(P, i \cap \text { tomorrow })
$$

(27) shows the derivation of an atelic predicate with the temporal adverb 'tomorrow'. In the derivation, the version of AT for temporal predicates is used, because when tomorrow is applied to the eventive predicate "john-run", a temporal predicate is returned. The non-past is then applied to this temporal predicate.

\section{a. János fut}

john run.NPST.3SG.INDEF

'John runs'

b. $\llbracket j o h n-r u n \rrbracket=\lambda e . j o h n-r u n(e)$

c. $\llbracket$ TOMORROW $\rrbracket=\lambda P \lambda i . \mathrm{AT}(P, i \cap$ tomorrow $)$

d. $\llbracket$ TOMORROW $($ john-run $) \rrbracket=\lambda P \lambda i \cdot \operatorname{AT}(P, i \cap$ tomorrow $)(\lambda e . j$ john-run $(e))$

$$
=\lambda i \cdot \operatorname{AT}(\lambda e[\text { john-run }(e)], i \cap \text { tomorrow })
$$

$=\lambda i \exists e[$ john-run $(e) \wedge \tau(e) \subseteq i \cap$ tomorrow $]$

e. $\llbracket \operatorname{NPAST}($ TOMORROW (john-run) $) \rrbracket=\lambda P \lambda w \cdot \forall w^{\prime}\left[w^{\prime} \in \operatorname{MB}(w, n o w) \longrightarrow w^{\prime} \in\right.$ $\operatorname{AT}(P,[$ now, $\infty))](\lambda i \exists e[$ john-run $(e) \wedge \tau(e) \subseteq i \cap$ tomorrow $])$

$=\lambda w \cdot \forall w^{\prime}\left[w^{\prime} \in \operatorname{MB}(w, n o w) \longrightarrow w^{\prime} \operatorname{AT}(\lambda i \exists e[\right.$ john-run $(e)] \wedge \tau(e) \subseteq i \cap$ tomorrow $),[$ now,$\infty)]$

$$
\begin{aligned}
& =\lambda w . \forall w^{\prime}\left[w^{\prime} \in \operatorname{MB}(w, n o w) \longrightarrow w^{\prime} \in \exists e[\operatorname{john}-\operatorname{run}(e) \wedge \tau(e) \subseteq[\text { now }, \infty) \cap\right. \\
& \text { tomorrow }]]
\end{aligned}
$$

The time at which the predicate holds is the intersection of tomorrow with the interval extending from now to infinity. This prevents ongoing or event-in-progress 


\section{Nicole Palffy-Muhoray}

readings from arising with any predicates, regardless of their telicity. Only a future reading is available.

\section{Conclusion}

In Hungarian, overt future marking is not always required for future reference, and it is aspect rather than tense which contributes to the forward-shifting of the event in these cases. This paper has provided an initial analysis of the non-past and fog constructions in Hungarian. On this account, the asymmetry in the distribution of ongoing and future-referring interpretations of non-past sentences falls out from the interaction of the telicity of the predicate with the temporal properties of the non-past.

It may be possible in future work to account for cross-linguistic variation in the functions of non-past constructions through similar mechanisms, in which the aspectual categories distinguished in a particular language interact with the semantics of a general non-past to give rise to certain interpretations.

\section{References}

Abondolo, D.M., 1998. The Uralic languages. Taylor \& Francis.

Abusch, D., 1998. Generalizing tense semantics for future contexts. Events and grammar 70:13-33.

Bittner, M., 2005. Future discourse in a tenseless language. Journal of Semantics 22(4):339.

Condoravdi, C., 2002. Temporal interpretation of modals. The construction of meaning 59-88.

Dahl, Ö., 2000. The grammar of future time reference in European languages. Tense and Aspect in the Languages of Europe 309-328.

Deo, A., 2009. Unifying the imperfective and the progressive: partitions as quantificational domains. Linguistics and philosophy 32(5):475-521.

Hayashi, M., 2011. The structure of multiple tenses in Inuktitut. Ph.D. thesis, University of Toronto.

Krifka, M., 1998. The origins of telicity. Events and grammar 197:235.

Lotz, J., 1962. Semantic analysis of the tenses in Hungarian. Lingua 11:256-262.

Papp, N., 1989. Future time and future tense in English and Hungarian. Annales Universitatis Scientiarum Budapestinensis Linguistica 5-31.

Smith, C.S., 2008. Time with and without tense. Time and modality 227-249.

Tonhauser, J., 2009. The Paraguayan Guarani future marker-ta: Formal semantics and cross-linguistic comparison. Tense Across Languages. Tübingen: Niemeyer (Linguistische Arbeiten).

Nicole Palffy-Muhoray

Linguistics Department 


\section{Future Reference in Hungarian}

Yale University

370 Temple St.

New Haven, CT 06511

nicole.palffy-muhoray@yale.edu 